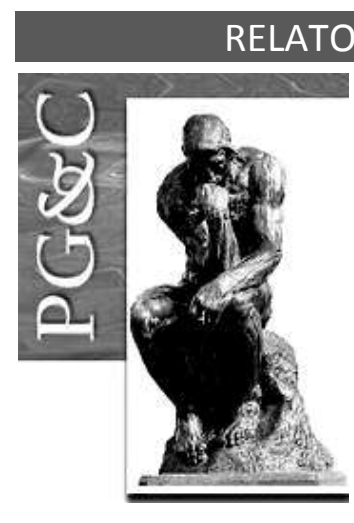

\title{
NARRATIVA NO FLUXO DE INFORMAÇÃO PARA O COMPARTILHAMETNO DE CONHECIMENTO EM MPE: PROPOSTA DE UM MODELO
}

\author{
Tatiana Cristina Siqueira dos Santos \\ Mestre em Ciência da Informação pela Universidade Federal de Santa \\ Catarina, Brasil. \\ E-mail: taticss@yahoo.com.br \\ Dorzeli Salete Trzeciak \\ Doutora em Engenharia de Produção pela Universidade Federal de Santa \\ Catarina, Brasil. \\ E-mail: dorzeli@hotmail.com \\ Gregório Varvakis Rados \\ Doutor em Engenharia de Produção pela Universidade Federal de Santa \\ Catarina, Brasil. Professor na Universidade Federal de Santa Catarina, \\ Brasil. \\ E-mail: g.varvakis@ufsc.br
}

\begin{abstract}
Resumo
O objetivo deste artigo é apresentar um modelo para descrever a narrativa no fluxo de informação para o compartilhamento de conhecimento, em micro e pequenas empresas. É uma pesquisa aplicada, com abordagem qualitativa, descritiva e utiliza a pesquisa bibliográfica como procedimento técnico para a sua realização. Na elaboração do modelo consideraram-se os elementos: emissor, receptor(es), mensagem (narrativa), fontes, formas de interação, mecanismos de suporte e barreiras. 0 modelo desenvolvido descreve como acontece a narrativa no fluxo de informação para o compartilhamento de conhecimento e, com isso, auxilia os gestores na reflexão e análise da narrativa como prática organizacional. A relevância do modelo se apoia nas etapas do processo de compartilhamento de conhecimento, na análise e descrição dos seus elementos de forma concisa, permitindo a sistematização da narrativa como um método capaz de sustentar o processo de melhoria contínua das micro e pequenas empresas.
\end{abstract}

Palavras-chave: Fluxo de informação. Narrativa. Compartilhamento de conhecimento em MPEs.

\section{NARRATIVE IN INFORMATION FLOW FOR KNOWLEDGE SHARING IN SME: PROPOSSAL OF A MODEL}

\begin{abstract}
This paper aims to present a model to describe the narrative in information flow for knowledge sharing in micro and small businesses. For this purpose, this research has a qualitative approach, descriptive and uses literature review as a technical procedure. The model considered the following elements: transmitter, receiver(s), the message (narrative), fonts, forms of interaction, support mechanisms, and barriers. The model describes how the narrative takes place in the information flow for knowledge sharing and, therefore, it helps managers in reflection and narrative analysis as organizational practice. The relevance of the model it based on concisely analysis and description of the knowledge sharing process and its steps, allowing the systematization of narrative as a method to support the continuous improvement process of micro and small businesses.
\end{abstract}

Keywords: Information flow. Narrative. Knowledge sharing in SMEs.

Perspectivas em Gestão \& Conhecimento, João Pessoa, v. 7, n. 1, p. 28-47, jan./jun. 2017. DOI: http://dx.doi.org/10.21714/2236-417X2017v7n1p28

http://periodicos.ufpb.br/ojs2/index.php/pgc. ISSN: 2236-417X. Publicação sob Licença (oc) EY-NC-ND 


\section{INTRODUÇÃO}

Muitas organizações, ao executarem os processos, as atividades e as tarefas interagem plenamente com dados, informações e conhecimentos, visto que são inerentes a todos os processos. Tanto interna quanto externamente à organização, a informação é um elemento que possibilita fazer a diferença nas mais variadas soluções. No entanto, a organização nem sempre percebe o seu valor (JORGE; VALENTIM, 2016).

No contexto das micro e pequenas empresas (MPEs), parte significativa das informações e conhecimento sobre o negócio centraliza-se na figura do gestor-proprietário. Deste modo, a performance desses empreendimentos está relacionada diretamente à habilidade dos gestores em aplicar seus conhecimentos de mercado e as tecnologias nas rotinas e nos procedimentos organizacionais (THORPE et al., 2005).

Com o olhar voltado ao conhecimento dos gestores e a sua disseminação na organização, o fluxo de informação é visto como um processo potencial para gerar conhecimento em cada indivíduo, desde que este compreenda a mensagem e a utilize para transformar situações pré-existentes (BARRETO, 2002).

Santos e Valentim (2014) salientam que o gerenciamento do fluxo de informação é fundamental para que a comunicação organizacional seja eficaz, pois ela tem influência positiva na compreensão do ambiente, nas tomadas de decisão, bem como nas ações realizadas. A ausência de um bom gerenciamento do fluxo de informação afeta diretamente a comunicação, acarretando ambiguidade ao ambiente da organização, além de dificultar as interações entre os indivíduos da organização.

O que se espera do fluxo de informação é, portanto, que o profissional no papel de receptor entenda a mensagem e utilize esse novo conhecimento para tornar-se mais apto para ações de melhorias, tanto para ele quanto para a organização.

Denning (2006) relata que neste cenário, o gestor da organização, na função de principal fonte de informação e mudanças nas pequenas empresas, tem como desafio liderar sua equipe de modo harmônico, estimulando-a com novos desafios e ao mesmo tempo criando condições para atingi-los.

Ao reconhecer essa realidade, Echeverría (2004) aponta que os paradigmas que guiam a atuação dos gerentes na era do conhecimento devem ser: transformar não por meio da imposição, mas com diálogo e interações narrativas, promovendo e participando de algumas conversas e, até mesmo, evitando a propagação de outras.

Nesse sentido, as narrativas se apresentam como formas de criação e de transmissão de conhecimento no ambiente organizacional, conduzindo os indivíduos para a ação (BOISOT; LI, 2006; BRUSAMOLIN, 2006; DENNING, 2006; GARGIULO, 2006).

Os processos de inovação e melhoria organizacional não ocorrem de forma sistemática e, sobretudo, são dependentes e influenciados internamente pelas experiências dos gestoresproprietários (WANG; COSTELLO, 2009). Nesse sentido, compreende-se que a narrativa é inerente à atividade de liderança e gestão nas organizações.

Com a abordagem voltada à capacidade de dinamismo dos pequenos empresários, sabendo-se que a vantagem competitiva encontra-se na aplicação de conhecimentos às rotinas e aos processos organizacionais, antes que os concorrentes o façam e, considerando que a forma como o conhecimento é articulado para produzir narrativas impacta na sua disseminação e utilização pela organização (BOISOT; MACMILLAN; HAN, 2007), pretende-se investigar neste estudo, de que forma, e a partir de quais elementos, pode ser estruturado um modelo para descrever como acontece a narrativa no fluxo de informação para o compartilhamento de conhecimento em MPEs. Portanto, este artigo tem como objetivo 
apresentar um modelo para descrever a narrativa no fluxo de informação para o compartilhamento de conhecimento em micro e pequenas empresas.

Este estudo está estruturado em: introdução, na qual se apresenta o contexto, a problemática e o objetivo do estudo; procedimentos metodológicos, com a descrição das etapas adotadas para a realização da pesquisa; fundamentação teórica, em que aborda-se a temática em estudo para identificar os subsídios necessários para a construção do modelo; modelo proposto para descrever a narrativa no fluxo de informação para o compartilhamento de conhecimento em MPEs; considerações finais do estudo e; as referências utilizadas.

\section{FUNDAMENTAÇÃO TEÓRICA}

Nesta seção apresenta-se a fundamentação teórica que deu subsídio para a construção do modelo, contemplando: realidade das MPEs de serviço, fluxos de informação, elementos do fluxo de informação e narrativa para o compartilhamento de conhecimento.

\subsection{Realidade das micro e pequenas empresas de serviço}

As MPEs, normalmente, enfrentam restrições de recursos, possuem infraestrutura organizacional simples e ausência de vínculos com comunidades científicas, o que impacta na sua capacidade de adquirir e implementar novos conhecimentos. Geralmente, as informações e os conhecimentos residem mais nas experiências anteriores dos gestores-proprietários, do que em equipes de pesquisa e desenvolvimento (WANG; WANG; HORNG, 2010).

No entanto, Jorge e Valentim (2016) consideram a informação e o conhecimento como elementos intrínsecos às atividades da organização e, deste modo, é fundamental identificar seu comportamento no ambiente organizacional em que está inserida. Para Nascimento et al. (2016) a tomada de decisão relaciona-se às possibilidades de escolha frente as diversas alternativas, o que leva o gestor a usar estratégias cognitivas baseadas em informação, visando resolver ou amenizar um problema da melhor forma possível.

Durst e Edvardsson (2012) salientam que as MPEs tendem a ser informais, não burocráticas, com estrutura plana e um estilo de gestão orgânico, livre de flutuação que estimula o empreendedorismo e a inovação. Entretanto, alguns autores, tais como Gassmann e Keupp (2007), apontam a problemática relacionada ao foco de investimento dos pequenos gestores-proprietários, que tendem a investir mais em ativos tangíveis do que em áreas relacionadas diretamente à vantagem competitiva da empresa - principalmente as de serviços - e à capacidade de seus funcionários melhorarem práticas e inovarem, com base em conhecimento.

O que se observa, é que as MPEs, em geral, são consideradas como criadoras de conhecimento, porém pobres na sua retenção (ALE EBRAHIM; AHMED; TAHA, 2010). Isso quer dizer que, ao mesmo tempo em que a estrutura das MPEs facilita a criação de novos conhecimentos, a maioria delas não está sistematizada para aproveitar todo o conhecimento existente e criar valor para o negócio.

Dessa forma, o compartilhamento de conhecimentos nas MPEs tende a acontecer em conversas de corredor ou em confraternizações da empresa (WONG; ASPINWAIL, 2005; DURST; WILHELM, 2012 apud DURST; EDVARDSSON, 2012).

Diante das peculiaridades das PMEs, considera-se, para este estudo, que elas não podem ser encaradas como versões reduzidas de grandes corporações. Em geral, elas são independentes, multitarefas, com o orçamento mais limitado e baseadas em relações mais pessoais e informais. Também são, comumente, gerenciadas pelos proprietários, altamente personalizadas e, em grande parte, locais em sua área de atuação e dependentes de recursos

Perspectivas em Gestão \& Conhecimento, João Pessoa, v. 7, n. 1, p. 28-47, jan./jun. 2017. 
internos para crescimento financeiro, e as suas demandas são impulsionadas pelo cliente (ALE EBRAHIM; AHMED; TAHA, 2010).

Thorpe et al. (2005) defendem a ideia de que o desempenho das PMEs está diretamente relacionado à habilidade dos gestores-proprietários, em integrarem seus conhecimentos e novas tecnologias aos procedimentos e fluxos de atividades da organização.

Pode-se considerar que nas PMEs, o gestor-proprietário é detentor do conhecimento. Por outro lado, o conhecimento está centrado nas pessoas e, nas MPEs devido às suas peculiaridades, os indivíduos possuem conhecimento de forma única, sendo esses conhecimentos complementares e raramente sobrepostos. Embora, em algumas situações, os resultados da prática possam ser semelhantes, dificilmente dois indivíduos farão uma mesma atividade de forma igual.

Portanto, para serem bem sucedidas, as MPEs precisam melhorar seus produtos (bens e serviços) e processos, explorando seu capital intelectual e os fluxos para o compartilhamento de conhecimentos, assuntos tratados na sequência.

\subsection{Fluxos de informação}

A existência dos fluxos de informação, de acordo com Cunha, Pereira e Neves (2015) resulta da relação existente entre dados, informação, conhecimento e inteligência. Num ambiente organizacional, os fluxos de informação dão suporte à tomada de decisão.

Fluxo de informação, de acordo com Barreto (1999) e Valentim (2010) é compreendido como um canal estruturado para sustentar melhores práticas (ações) a partir da transmissão de informações que estimulem processos cognitivos de criação de novos conhecimentos. Nesse contexto, informações são "estruturas simbolicamente significantes com a competência de gerar conhecimento no indivíduo, em seu grupo, ou na sociedade" (BARRETO, 1999, p. 70).

Para Inomata, Araújo e Rados (2015), os fluxos de informação são processos variáveis, dependentes de um conjunto de aspectos influenciadores que incidem sobre eles. No contexto organizacional, os fluxos de informação proporcionam a criação de valor à informação, permitindo que as atividades organizacionais ocorram para atender as necessidades da organização.

Santarém e Vitoriano (2016) argumentam que é indispensável o mapeamento e a compreensão dos fluxos de informação, pois permitem que a organização obtenha vantagem competitiva, devido ao diferencial que é dado ao tratamento e uso das informações e conhecimentos (SANTARÉM; VITORIANO, 2016).

Na visão de Santos e Valentim (2014), a dinâmica dos fluxos de informação é decisiva para que as ações organizacionais sejam efetivas, considerando-se que os fluxos são ligados aos processos, atividades e tarefas que se realizam nesse contexto, tanto formal quanto informalmente.

Assim como para Barreto (1999), entende-se, para o propósito deste artigo, o conhecimento como um processo, ou seja, um fluxo de informação que se potencializa a partir da assimilação da informação pelo receptor e a constituição, por este, de novos conhecimentos, dessa forma, dentro de algum contexto a disseminação de informação é considerada conhecimento.

Pesquisas na área de Ciência da Informação apontam que há vários modelos teóricos que ilustram os fluxos de informação (CURTY, 2005; INOMATA, 2012; PASSOS, 2012). Todavia, o foco deste estudo é estudar os fluxos no contexto organizacional, internos à organização e criados e disseminados pelos gestores-proprietários com destino a sua equipe de trabalhadores. Desta forma, foram selecionados modelos de fluxos que melhor representam a proposta deste estudo e que figuram entre os mais referenciados na literatura científica. Tais modelos são descritos no Quadro 1.

Perspectivas em Gestão \& Conhecimento, João Pessoa, v. 7, n. 1, p. 28-47, jan./jun. 2017. 
Quadro 1 - Resumo dos modelos de fluxo de informação estudados

\begin{tabular}{|c|c|c|}
\hline Modelos & Abordagem & Fases \\
\hline $\begin{array}{l}\text { Modelo de } \\
\text { Lesca e } \\
\text { Almeida } \\
\text { (1994) }\end{array}$ & $\begin{array}{l}\text { Abordagem estratégica da informação } \\
\text { para a rotina do gestor com a } \\
\text { apresentação de três fluxos que } \\
\text { consideram a organização e o ambiente } \\
\text { mercadológico na qual está inserida. } \\
\text { Descreve os tipos de informação } \\
\text { contidos em cada um dos fluxos. }\end{array}$ & $\begin{array}{l}\text { (1) Fluxo de informação captado } \\
\text { externamente à empresa e utilizada por } \\
\text { ela; (2) Fluxo de informação produzido } \\
\text { pela empresa para uso interno; e (3) } \\
\text { Fluxo de informação produzido pela } \\
\text { empresa e orientado para fora dela. }\end{array}$ \\
\hline $\begin{array}{l}\text { Modelo de } \\
\text { Choo (2006) }\end{array}$ & $\begin{array}{l}\text { Abordagem complexa de fluxo de } \\
\text { informação organizacional, como forma } \\
\text { estruturada de administrar a } \\
\text { informação por meio de processos } \\
\text { relacionados em seis etapas e } \\
\text { finalizados com o comportamento } \\
\text { adaptativo que o autor considera como } \\
\text { resultado das etapas anteriores, ou } \\
\text { seja, uma ou mais ações práticas } \\
\text { resultantes do fluxo de informações, } \\
\text { cujos resultados refletem em novos } \\
\text { ciclos de uso da informação. }\end{array}$ & 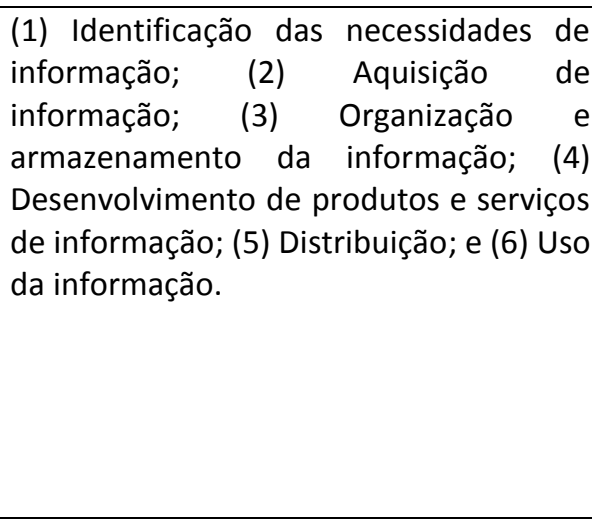 \\
\hline $\begin{array}{c}\text { Modelo de } \\
\text { Barreto (2001) }\end{array}$ & $\begin{array}{l}\text { Abordagem cognitiva, mais próxima de } \\
\text { uma abordagem em nível individual. O } \\
\text { modelo considera o fluxo da fonte } \\
\text { emissora para um receptor, } \\
\text { diretamente ou por meio de registro } \\
\text { em um sistema de armazenamento e } \\
\text { recuperação. }\end{array}$ & $\begin{array}{l}\text { (1) Fluxo de } 1 \text { o nível (entre autor e o } \\
\text { sistema de informação): o autor } \\
\text { considera o movimento entre os } \\
\text { elementos do sistema de } \\
\text { armazenamento e como se orientam } \\
\text { para sua organização e controle (gestão } \\
\text { da informação); (2) Fluxo de } 2 \text { o nível } \\
\text { (entre emissor e receptor) considera-se } \\
\text { a transformação entre a linguagem do } \\
\text { pensamento e a linguagem de inscrição } \\
\text { do emissor autor da informação } \\
\text { (processo de criação da informação) e o } \\
\text { conhecimento elaborado e assimilado } \\
\text { pelo receptor em sua realidade. }\end{array}$ \\
\hline $\begin{array}{l}\text { Modelo de } \\
\text { Boisot e Li I- } \\
\text { SPACE (2006) }\end{array}$ & $\begin{array}{l}\text { Abordagem cognitiva baseada na } \\
\text { representação do movimento da } \\
\text { informação dentro do cubo } \\
\text { tridimensional l-Space para a } \\
\text { disseminação do conhecimento } \\
\text { individual e incorporado. O fluxo de } \\
\text { difusão do conhecimento parte de } \\
\text { processos de estruturação do } \\
\text { conhecimento (codificação e abstração) } \\
\text { em nível individual, para transformá-lo } \\
\text { em formatos aplicáveis e acessíveis a } \\
\text { todos na organização, atingindo o nível } \\
\text { organizacional. }\end{array}$ & $\begin{array}{ll}\text { (1) Conhecimento incorporado; } & \text { (2) } \\
\text { Conhecimento narrado; e } & \text { (3) } \\
\text { Conhecimento abstrato simbólico. }\end{array}$ \\
\hline $\begin{array}{c}\text { Modelo de } \\
\text { Boisot (1998) }\end{array}$ & $\begin{array}{l}\text { Certo de que o conhecimento dos } \\
\text { indivíduos só alcança suas } \\
\text { potencialidades máximas para criar }\end{array}$ & $\begin{array}{l}\text { (1) Exploração e identificação das } \\
\text { ameaças e oportunidades para produzir } \\
\text { padrões e insights; }(2) \text { Codificação e }\end{array}$ \\
\hline
\end{tabular}

Perspectivas em Gestão \& Conhecimento, João Pessoa, v. 7, n. 1, p. 28-47, jan./jun. 2017. 


\begin{tabular}{|c|c|c|}
\hline & $\begin{array}{l}\text { valor quando são absorvidos pelas } \\
\text { rotinas organizacionais, Boisot (1998), } \\
\text { na perspectiva do cubo tridimensional } \\
\text { l-Space, aborda o movimento do } \\
\text { conhecimento descrevendo em seis } \\
\text { fases a conversão dos conhecimentos } \\
\text { individuais em conhecimentos } \\
\text { organizacionais. }\end{array}$ & $\begin{array}{l}\text { estruturação dos elementos } \\
\text { identificados de dados e informações, a } \\
\text { fim de reduzir as incertezas e os desafios } \\
\text { de conhecimento existentes; (3) } \\
\text { Abstração e generalização da estrutura } \\
\text { obtida de dados e informações; (4) } \\
\text { Difusão e compartilhamento do } \\
\text { conhecimento obtido com grupos-alvo; } \\
\text { (5) Absorção do novo conhecimento por } \\
\text { meio do conhecer fazendo; e (6) } \\
\text { Incorporação do conhecimento na } \\
\text { prática, impactando em produtos, } \\
\text { técnicas e comportamento } \\
\text { organizacional. }\end{array}$ \\
\hline $\begin{array}{c}\text { Modelo de } \\
\text { Tonet e Paz } \\
\text { (2006) }\end{array}$ & $\begin{array}{l}\text { Apresenta o compartilhamento de } \\
\text { conhecimento como um processo } \\
\text { integrado por um conjunto de quatro } \\
\text { fases que disseminam informações, } \\
\text { ideias, sugestões e experiências, } \\
\text { organizacionalmente relevantes. }\end{array}$ & $\begin{array}{l}\text { (1) Iniciação: caracterizada por ações } \\
\text { voltadas para identificar e analisar as } \\
\text { necessidades de conhecimentos, e as } \\
\text { oportunidades existentes para empregar } \\
\text { conhecimentos diferentes ou novos; (2) } \\
\text { Implementação: com ações voltadas } \\
\text { para promover a integração entre fontes } \\
\text { (emissores) e destinatários (receptores) } \\
\text { do conhecimento; (3) Apoio: } \\
\text { caracterizada por ações voltadas para } \\
\text { criar oportunidades de exercitamento do } \\
\text { conhecimento compartilhado e para } \\
\text { promover orientação da prática, até que } \\
\text { ocorra a assimilação do conhecimento e } \\
\text { o desenvolvimento das habilidades } \\
\text { necessárias ao uso proficiente; e (4) } \\
\text { Incorporação: fase configurada por } \\
\text { ações voltadas para fazer com que o } \\
\text { conhecimento compartilhado possa fluir } \\
\text { livremente entre aqueles que deverão } \\
\text { usá-lo. }\end{array}$ \\
\hline
\end{tabular}

Fonte: Levantamento teórico do estudo

A seleção dos modelos de fluxo apresentada no Quadro 1 oferece um panorama geral da forma como os canais são estruturados para disseminarem informação e conhecimentos nas organizações, oferecendo elementos que contribuíram para conduzir a temática fluxo de informação neste estudo, como é destacado a seguir.

A abordagem de Lesca e Almeida (1994) permitiu construir uma visão de trabalho dos fluxos sob o ponto de vista dos micro e pequenos estabelecimentos, nos quais os gestoresproprietários são os principais responsáveis por buscar fontes externas e traduzir essas informações e conhecimentos em conhecimentos úteis para a organização, a fim de criar os fluxos internos.

O modelo de Choo (2006) indica uma estruturação para os fluxos internos da organização como ferramenta administrativa para aproveitar a experiência e o conhecimento de seus membros, por meio da criação de significados comuns, exploração de novos conhecimentos e comprometimento com certos cursos de ação.

A abordagem tratada por Barreto (2001) e Boisot e Li (2006), proporcionou uma visão da narrativa centrada na figura do gestor-proprietário e na articulação de seus conhecimentos.

Perspectivas em Gestão \& Conhecimento, João Pessoa, v. 7, n. 1, p. 28-47, jan./jun. 2017. 
Boisot (1995) enfatiza o conhecimento tácito incorporado e sua trajetória na construção do conhecimento em nível organizacional e na capacidade de inovar das organizações.

Os modelos de Choo (2006), Boisot (1995) e Tonet e Paz (2006) apresentaram genericamente a etapa de incorporação e uso, a qual devidamente monitorada pela gerência evidenciará o impacto da adoção do novo conhecimento pela organização e de mecanismos que ofereçam condições para que ele flua de forma acessível.

Portanto, entende-se que o gestor desenvolve e articula seus conhecimentos, tanto em nível individual quanto organizacional, por meio de construções narrativas, levando a organização a ampliar sua capacidade de ação, na medida em que eles são aceitos e assimilados pelo receptor, gerando melhores práticas, além de retroalimentarem a base cognitiva de conhecimentos dos indivíduos e da organização.

\subsection{Elementos do fluxo de informação}

No que se refere aos elementos que caracterizam o fluxo de informação, realizou-se um levantamento, com o propósito de compreendê-los como as principais variáveis de análise e, com isso, levantar subsídios para auxiliar na construção do modelo que descreve a narrativa no fluxo de informação para o compartilhamento de conhecimento em MPEs, foco deste estudo. A síntese dos elementos estudados é apresentada no Quadro 2.

Quadro 2-Quadro conceitual sobre elementos do fluxo de informação

\begin{tabular}{|l|l|}
\hline \multicolumn{1}{|c|}{ Elementos do fluxo de informação } & \multicolumn{1}{|c|}{ Autores } \\
\hline $\begin{array}{l}\text { Atores (emissores e receptores): o produtor de informação (emissor) tem o } \\
\text { domínio sobre a oferta de informação e por isso decide sobre quais informações } \\
\text { devem ser estocadas e quais as estratégias de disseminação, bem como, sobre o } \\
\text { uso de tecnologias para definir os canais. O receptor é aquele que deve assimilar e } \\
\text { utilizar o conhecimento recebido. }\end{array}$ & \\
\hline $\begin{array}{l}\text { Canais e fontes: canais são constituídos pela circulação de informações que fluem } \\
\text { de uma determinada origem (fonte), geralmente um emissor, em sentido a um } \\
\text { repositório ou para ser processada por um receptor. }\end{array}$ & 2010) \\
\hline $\begin{array}{l}\text { Tecnologias da informação e comunicação (TIC): a TIC pode auxiliar no } \\
\text { armazenamento e recuperação de informações necessárias e de outros } \\
\text { documentos relevantes, servindo como opção de canal de informação. }\end{array}$ & (CHOO, 2006) \\
\hline $\begin{array}{l}\text { Barreiras: fatores que dificultam o processo de comunicação, disseminação e } \\
\text { criação do conhecimento, tais como: falta de domínio sobre o conhecimento } \\
\text { pelos emissores ou fontes; níveis de comunicação (intra, inter, grupal e coletivo); } \\
\text { forma de organização do fluxo de informação e comunicação e; problemas com os } \\
\text { tipos de canais. }\end{array}$ & SAS, 2009) \\
\hline
\end{tabular}

Fonte: Levantamento teórico do estudo

Entende-se que, para gerar valor à organização deve haver uma conexão entre o emissor e o receptor, para que esse possa refletir sobre o novo conhecimento e reconhecê-lo como importante para si próprio e para o seu trabalho (TONET; PAZ, 2006). Neste sentido, é importante a forma como o receptor percebe uma fonte em um contexto no qual a informação é recebida. Os canais de comunicação, por sua vez, impactam na qualidade dos processos de absorção e incorporação do novo conhecimento. Conforme Choo (2006) os canais de comunicação utilizados pelas pessoas face a face são ricos, pois permitem lidar com incertezas e indefinições, concentrar-se nos reais problemas, solucionar diferenças e estimular a criatividade. Tanto para o armazenamento e recuperação quanto para trocas e interações entre emissores e receptores, as TICs também são excelentes opções de canais. Porém, para 
este estudo, são reconhecidas como elemento de suporte aos conhecimentos trocados pessoalmente, pois não substituem os fluxos orais e pessoais, fortemente presentes nos fluxos de informação conduzidos pelos gestores nas MPEs.

\subsection{Narrativa}

A narrativa faz parte de um processo cultural, em que os sistemas simbólicos criam e são criados por meio do discurso e é utilizada em diferentes contextos, a fim de comunicar pontos de vista (SCHREIBER, 2016).

Na visão de Brusamolin (2011), narrativas de histórias ou simplesmente narrativas, são relatos orais ou escritos, de um ou mais eventos, verdadeiros ou fictícios. A diferença entre uma história e a citação de um exemplo, conforme o autor está na adição de conteúdo emocional e detalhes sensoriais na narrativa. Com base nisso, entende-se que é possível sim transformar um exemplo, fato ou experiência em uma história, na medida em que são estruturados como tal.

Muitos gerentes recorrem à narrativa como poderosa ferramenta para descobrir meios de expressar o indizível, utilizando a linguagem figurativa e simbólica para articular suas intuições e insights e disseminar seu conhecimento incorporado (tácito) (NONAKA, 2000). Para esse autor, o uso de metáfora, analogia e modelo correspondem às funções que captam o processo de explicitação de conhecimento, sendo que podem estar presentes mais de uma dessas funções em uma mesma narrativa.

Gargiulo (2006) aborda a construção narrativa como histórias, apontando três funções pertinentes a elas que facilitam a comunicação e a disseminação de conhecimento: dão poder ao narrador (emissor) e ajudam-no a criar um ambiente; codificam informações; e são uma ferramenta para pensar.

$\mathrm{Na}$ medida em que o narrador articula seus conhecimentos para que o receptor construa seu entendimento, aos poucos, a experiência vai sendo experimentada pelo ouvinte e os elementos contidos na narrativa oferecem estímulos, que despertam novos pensamentos e insigths (SOLE; WILSON, 2002).

No mundo dos negócios, segundo Denning (2006), os pensamentos são alimentados pela análise de fatos e dados, a apresentação de argumentos lógicos e a objetividade. E neste ponto, o autor reconhece que é papel da liderança inspirar as pessoas para agirem com energia e entusiasmo.

As narrativas, quando adequadamente empregadas, são ferramentas que podem aumentar o poder de liderança do emissor, por meio da elaboração de mensagens, construídas a partir da articulação entre conhecimentos codificados e experienciais (incorporados), estruturadas, conforme o grau de codificação e abstração, com o uso de metáforas, analogias, exemplos, fatos, histórias para atingir propósitos claros e bem definidos (GARGIULO, 2006; NONAKA, 2000; SOLE, WILSON, 2002; DENNING, 2006). Sob o enfoque dos receptores, entende-se que essas narrativas oferecem subsídios para que a compreendam a sua maneira e desenvolvam suas próprias histórias de ação, na direção dos propósitos organizacionais (BRUSAMOLIN, MORESI, 2008; LIPMAN, 1999 apud BRUSAMOLIN, 2011).

As narrativas são empregadas nas organizações essencialmente para compartilhar conhecimentos relacionados a práticas e contextos. Denning (2006) apresenta oito padrões de narrativas com base na finalidade, os quais podem ser aplicados para: desencadear uma ação (mudança) e implementar novas ideias; comunicar quem você é; comunicar o que a empresa é; transmitir valores; incentivar uma atitude colaborativa; acabar com fofocas; compartilhar conhecimento; e liderar em direção ao futuro.

Estudo realizado por Sole e Wilson (2002) indica que histórias podem ser particularmente úteis nos contextos nos quais se deseja lançar uma ideia nova, socializar

Perspectivas em Gestão \& Conhecimento, João Pessoa, v. 7, n. 1, p. 28-47, jan./jun. 2017. 
novos membros, mediar relacionamentos e compartilhar sabedoria e melhores práticas. Os autores ainda apontam que a técnica de articular histórias na narrativa (storytelling) é uma forma de compartilhar conhecimentos tácitos simples.

Segundo Denning (2006), a essência da narrativa está na capacidade de persuadir, conquistar "corações e mentes" das pessoas - que caracteristicamente avançam por indução, argumento por argumento, exemplo por exemplo - e liderá-las em direção a uma visão mais ampla sobre o significado da atividade que exercem a fim de que, desse modo, tenham mais força e entusiasmo para desenvolver a prática.

Neste sentido, compreende-se a construção narrativa como um roteiro que suporta ou é suportado pelos demais modos de compartilhar conhecimento, dependendo do ponto de vista (emissor ou receptor), oferecendo maior coerência ao fluxo de informação.

Brusamolin e Moresi (2008) apresentam um modelo cíclico de criação e emprego de narrativas composto de seis etapas que servem de roteiro para o gestor, detalhadas a seguir:

a) monitorar o ambiente: indica que o gerente deve estar sempre atento ao ambiente, a fim de perceber os problemas que podem impedir o sucesso da atividade e saber a oportunidade adequada, bem como as pessoas que devem ouvir determinada narrativa;

b) definir a situação existente: baseia-se na pergunta: "qual é o problema?". O objetivo é auxiliar a externalização do contexto que deveria ser modificado. A situação existente define o diagnóstico de um contexto que, na percepção do gerente, esteja trazendo ou possa vir a trazer prejuízos ao desenvolvimento da organização;

c) definir a situação desejada: ter claro o contexto adequado para o sucesso do negócio, para, a partir dele, identificar o gap (entre situação existente e situação desejada) e determinar o verdadeiro propósito da intervenção;

d) construção e seleção das histórias: consiste na construção de uma ou mais histórias que possam desencadear mudanças no ambiente, transpondo-o da situação existente para a desejada. Na sequência, a etapa de selecionar histórias é complexa, pois exige compreensão do ambiente e um palpite sobre como a audiência irá interpretar a história. Essa habilidade é adquirida por meio do conhecimento do contexto e da audiência, mas mesmo assim, não se pode ter certeza de como a história será interpretada;

e) narrativa da história: esta etapa deve ser conduzida de maneira natural. Em narrativas organizacionais, não há necessidade de o narrador fazer uma performance. Ou seja, modificar seu tom de voz e comportamento usual, pois a narrativa deve ter credibilidade, e tudo que a envolve deve ser verdadeiro, inclusive os gestos do narrador, que deve ter em mente que está simplesmente compartilhando um conhecimento com outros indivíduos;

f) observando o que aconteceu: o gerente deve acompanhar os resultados da narrativa para verificar se a situação existente evoluiu para a desejada. Caso isso não tenha acontecido, identificar quais os possíveis impedimentos para a mudança, projetar novas interações narrativas e reiniciar o ciclo.

Considera-se, portanto, o modelo de Brusamolin e Moresi (2008) como um fluxo elaborado com a finalidade de compartilhar conhecimento para gerar uma mudança (ação), no qual as mensagens são construções narrativas. Assim sendo, narrativas são mensagens estruturadas com propósitos de criar conhecimento e liderar para a ação, facilitando a disseminação dele na organização (BOISOT; LI, 2006; BRUSAMOLIN; 2006; DENNING, 2006; GARGIULO, 2006). Para isso, utiliza os artifícios da linguagem simbólica, da expressão corporal e da entonação de voz (quando face a face), ou outras formas de suporte (narrativa de 
histórias/storytelling, observação, simulação, recursos codificados e objetos simbólicos) (NONAKA, 2000; SOLE; WILSON, 2002).

Verificou-se, assim, a narrativa presente em dois momentos no fluxo de informação: para criar e para disseminar conhecimento, isto é a criação de conhecimento sob a perspectiva cognitiva (na mente do emissor e receptor) relacionada à estrutura do pensamento e da mensagem; e a disseminação de acordo com a estrutura do fluxo de informação da organização, considerando que esses aspectos (criação e disseminação) se retroalimentam.

\section{PROCEDIMENTOS METODOLÓGICOS}

Do ponto de vista da sua natureza, esta pesquisa enquadra-se como aplicada, tendo como característica principal contribuir para fins práticos, isto é, aplicar ou utilizar, mais ou menos imediatamente, os resultados na solução de problemas que ocorrem na realidade (MARCONI; LAKATOS, 2007).

Quanto à abordagem do problema, trata-se de pesquisa qualitativa, entendida como um processo não matemático de interpretação, que objetiva descobrir conceitos e relações nos dados brutos e organizar esses conceitos e relações em um esquema explanatório teórico (STRAUSS; CORBIN, 2008). Portanto, com a caracterização de alguns modelos e elementos de fluxo de informação e narrativa, revisados na literatura, lança-se mão de uma abordagem qualitativa, no intuito de identificar subsídios para a elaboração de uma proposta de modelo para descrever a narrativa no fluxo de informação para o compartilhamento de conhecimento.

No que e refere aos seus objetivos, é descritiva. Os estudos descritivos têm como principal objetivo descrever as características de determinada população ou fenômeno, ou estabelecer relações entre variáveis (GIL, 2002). Desta forma, a pesquisa procura descrever como acontece a narrativa no fluxo de informação sem o desígnio de explicar o porquê da sua existência.

Como procedimento técnico, utilizou-se a pesquisa bibliográfica. As buscas pela literatura - teses, dissertações e artigos - foram realizadas nas bases de dados BRAPCI, Scopus e WoS (ISI), com o uso dos descritores 'narrativa' (em inglês: 'narrative') e 'uso da narrativa' (em inglês: 'use of narrative') como filtros para o tema disseminação e compartilhamento de conhecimento. Com a intenção de selecionar documentos relacionados apenas à administração de negócios, os resultados não foram satisfatórios, pois a maioria dos documentos recuperados relacionava-se à psicologia, literatura, linguagem ou utilizavam a narrativa de histórias como método de coleta e análise de dados. Diante isso, adotou-se uma nova estratégia de investigação, utilizando o termo storytelling. Foram encontrados muitos artigos relacionados à gestão do conhecimento e, destes, selecionaram-se apenas aqueles que se referiam a negócios para fundamentar o estudo. $O$ período de realização deste estudo foi de 2013 a 2014, atualizado em 2016.

\section{MODELO PROPOSTO DANARRATIVA NO FLUXO DE INFORMAÇÃO PARA O COMPARTILHAMENTO DE CONHECIMENTO}

O modelo de análise da narrativa no fluxo de informação para o compartilhamento de conhecimento tem como finalidade auxiliar na compreensão e descrição de como ocorre a narrativa no ambiente das pequenas organizações, discutir os elementos que integram esse processo, e buscar, desta forma, contribuir para a melhoria de práticas no ambiente organizacional.

Neste sentido, este item trata dos pressupostos para a construção do modelo da narrativa no fluxo de informação para o compartilhamento de conhecimento, bem como dos elementos que o compõe.

Perspectivas em Gestão \& Conhecimento, João Pessoa, v. 7, n. 1, p. 28-47, jan./jun. 2017. 


\subsection{Pressupostos para a construção do modelo}

$\mathrm{Na}$ elaboração do modelo, considerou-se a estrutura de fluxos internos e os tipos de informações, com base em Lesca e Almeida (1994) para que a proposta contribuísse no atendimento da necessidade interna de conhecimento da organização. Do modelo de fluxo de informação elaborado por Barreto (2002), com uma abordagem mais cognitiva, considerou-se do fluxo entre o emissor e o receptor, aquele que contempla o processo de transformar o conhecimento do emissor em uma mensagem. Essa mensagem é compreendida neste estudo como narrativa, embasados no I-Space de Boisot e Li (2006) para entender que a disseminação do conhecimento é uma evolução gradativa do conhecimento incorporado em disseminado, à medida que se articula por meio de narrativas e outros esforços de codificação, para se chegar a uma mensagem que faça sentido a um número maior de indivíduos em uma organização.

De Sole e Wilson (2002), adotaram as diversas formas de compartilhar conhecimento como importantes para suportar a mensagem narrada. Os estudos de Brusamolin (2006) e Denning (2006) contribuíram para o entendimento sobre o uso da narrativa no ambiente organizacional como ferramenta de gestão. Considerou-se no modelo do fluxo de informação, o uso da narrativa composta por informações e conhecimentos para vencer as barreiras da comunicação, criar sentido e impulsionar o receptor para agir (WEICK; SUTCLIFFE; OBSTFELD, 2005). No que tange à estrutura básica do fluxo de informação (atores, canal, fontes, mensagem e barreiras), os trabalhos de Valentim (2010), Curty (2005), Inomata (2012) e Passos (2012) serviram de guias.

A Figura 1 ilustra o modelo da narrativa no fluxo de informação, que parte da essência da composição de um fluxo de informação: emissor, receptor e mensagem, na qual esta é a narrativa. A partir disso, a leitura que se pode fazer do modelo é o destaque proposto centralizado na pessoa que emite o conhecimento, o emissor (gestor-proprietário, nas MPEs) e, em torno dele, sob seus domínios, os elementos monitoramento do ambiente, fontes, formas de interação, mecanismos de suporte e mensagem.

Figura 1 - Modelo da narrativa no fluxo de informação

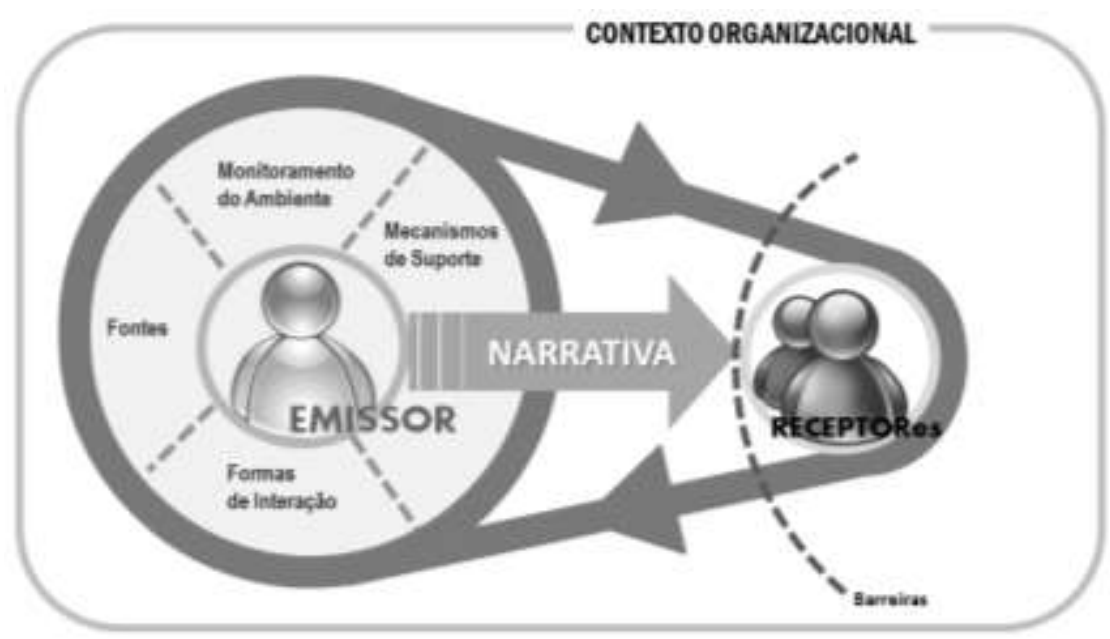

Fonte: Elaborado pelos autores

O emissor sustenta o fluxo monitorando o ambiente e identificando as oportunidades que o motivam a interagir com alguém, o receptor. No entanto, para a interação produzir os resultados desejados, o emissor seleciona adequadamente em suas fontes, argumentos, exemplos, metáforas, documentos impressos, manuais, ou seja, mecanismos que suportam a

Perspectivas em Gestão \& Conhecimento, João Pessoa, v. 7, n. 1, p. 28-47, jan./jun. 2017. 
mensagem central que deseja transmitir e, da mesma forma, determina a forma de interação que se demonstre mais adequada. A mensagem narrativa é construída pelo emissor para conectar as informações e conhecimentos, suportados ou não por elementos físicos (dependendo do grau de codificação), e conferir a eles um sentido. $O$ uso estratégico desses elementos tem como propósito vencer as barreiras da comunicação e do compartilhamento de conhecimento e atingir os objetivos de disseminar novos conhecimentos, desenvolver competências e mudar comportamentos.

Nesse sentido, de modo a alcançar o propósito da construção do modelo, a definição dos 8 elementos de análise ocorreu a partir da interpretação dos elementos básicos: atores, fontes e canais, mensagem e barreiras.

Os elementos: (1) Emissor, (2) Receptor(es) e (8) Barreiras foram considerados sem alteração, por serem elementos naturalmente variáveis, de acordo com a caracterização e abordagem da pesquisa. $O$ elemento (3) Mensagem, na abordagem desta pesquisa, trata-se da narrativa. Os elementos (5) Fontes de argumento, (6) Formas de interação e (7) Mecanismos de suporte surgiram dos elementos "fontes e canais". Dessa maneira, o elemento fontes de argumento são fontes, as formas de interação são canais e os mecanismos de suporte são amplificações de canais e fontes, que visam sustentar a narrativa com a aplicação de outros métodos de compartilhamento de conhecimentos.

Os elementos tradicionais do fluxo de informação "fontes e canais" foram renomeados de "fontes de argumentos e formas de interação", respectivamente, para abranger a perspectiva do compartilhamento de conhecimento.

O elemento (4) Monitoramento do ambiente emergiu da necessidade de identificar as formas de controle e acompanhamento da incorporação do novo conhecimento compartilhado por meio da narrativa. Esse elemento é apresentado em duas etapas nos modelos de fluxo estudados no referencial: no início - identificação de necessidade; e no fim incorporação do conhecimento. Este último, embora não caracterizado como variável nas pesquisas levantadas sobre análise do fluxo de informação é incorporado, então, aos elementos de análise para atender aos propósitos do modelo desenvolvido.

\subsection{Elementos do modelo da narrativa no fluxo de informação}

Neste tópico, apresenta-se o detalhamento dos 8 elementos do modelo, de acordo com os parâmetros de análise e descrição da narrativa no fluxo de informação para o compartilhamento de conhecimento, na perspectiva dos gestores em MPEs.

\section{(1) Emissor}

O emissor do fluxo de informação narrativa atua como um produtor de informação e possuidor de conhecimento para interagir com receptores e estabelecer significados comuns, desenvolver competências e mudar comportamentos para alcançar os objetivos organizacionais (CHOO, 2006).

O emissor, de acordo com Gonçalvez, Ramos e Santos (2009) e Tonet e Paz (2006) caracteriza-se como alguém dotado de habilidades de comunicação, motivado para o repasse do conhecimento e ainda, possuidor de bom domínio sobre o conhecimento a ser repassado.

\section{(2) Receptor(es)}

Receptores são os indivíduos que apresentam a expectativa ou a necessidade de adquirir determinado conhecimento. A necessidade, muitas vezes, pode não estar clara para o receptor, e a aquisição do conhecimento pode representar um desafio significativo para ele, em particular se exigir o abandono de práticas já dominadas (TONET; PAZ, 2006).

Perspectivas em Gestão \& Conhecimento, João Pessoa, v. 7, n. 1, p. 28-47, jan./jun. 2017. 
Conforme Brusamolin (2008), os principais receptores com os quais os gestores interagem em sua rotina são: profissionais (equipe); clientes; fornecedores; gerentes e sócios e; outros gestores e empresários.

\section{(3) Narrativa (mensagem)}

A narrativa é a mensagem a ser compartilhada e, segundo Tonet e Paz (2006), o conteúdo presente nessa mensagem precisa ter validade e utilidade.

Validade e utilidade estão relacionadas à aplicação da mensagem, ao quanto e ao como o conhecimento transmitido atende às demandas ou necessidades que deram origem ao processo de compartilhamento (THAYER, 1979 apud TONET; PAZ, 2006).

As mensagens que fazem parte do fluxo de informação produzido pela empresa para consumo dela mesma, conforme modelo de Lesca e Almeida (1994), podem ser caracterizadas como informações de convívio e informações de atividade. As informações de convívio são aquelas que possibilitam aos indivíduos conviver e interagir, permitindo também influenciar em seus comportamentos e tem como funções principais: dar sentido à existência do trabalho, permitindo saber para que serve o que se está fazendo e como se está situado em relação aos outros membros da empresa, saber o que, por quê, etc. As informações de atividade englobam todo tipo de informação necessária para iniciar, realizar e controlar as operações relacionadas ao funcionamento da empresa, podendo ser em nível operacional e/ou estratégico.

\section{(4) Monitoramento do ambiente}

Esta etapa deve ser uma atividade constante da gestão, para acompanhar a situação existente (atual) e identificar uma oportunidade (motivação) para interagir e compartilhar conhecimento de acordo com propósitos estabelecidos, para, com base no gap identificado, compreender as principais situações nas quais o emissor percebe oportunidade e se motiva para compartilhar conhecimento. Porque, a partir dela, poderão ser instituídos os propósitos da narrativa para estudar a melhor estratégia de interação, além de identificar as principais práticas que podem ser empregadas para estabelecer um contexto propício à criação e compartilhamento de conhecimento (BRUSAMOLIN, 2006; CLARKE; MONKHOUSE, 1995 apud TONET; PAZ, 2006; DENNING, 2006; SOLE; WILSON, 2002; TONET; PAZ, 2006). Desse modo, a descrição do elemento monitoramento do ambiente envolve a apresentação de cinco subelementos: motivação, propósitos, práticas de manutenção, percepção de assimilação e práticas de controle.

A motivação, que dá início ao processo de compartilhamento de conhecimento, do ponto de vista do emissor, pode ser definida com base em três fatores: conhecimento restrito, desempenhos insuficientes e erros repetidos. $O$ item conhecimento restrito significa dizer que existem conhecimentos que podem ser compartilhados e estão restritos a uma ou poucas pessoas na organização. Assim, se estes conhecimentos não forem compartilhados poderão proporcionar a existência de fatores desfavoráveis à organização, prejuízos, erros repetidos e a não obtenção de resultados (CLARKE; MONKHOUSE, 1995 apud TONET; PAZ, 2006).

Quando há clareza da situação existente e uma boa definição da situação desejada, é possível estabelecer o(s) propósito(s) da intervenção narrativa. Desse modo, quando o emissor cria uma narrativa, ele o faz para atingir determinados objetivos que, com base em Brusamolin e Moresi (2008), Sole e Wilson (2002) e Denning (2006), são: transmitir e exemplificar a cultura organizacional, normas, políticas e valores; modificar e controlar comportamentos; resolver determinados problemas; gerenciar mudanças; estimular a criatividade e inovação; melhorar a sua imagem e a da sua empresa, comunicar quem você é os objetivos da empresa; transferir um novo conhecimento, experiências, melhores práticas; treinar funcionários; transmitir sua visão de futuro; estimular a colaboração, construir confiança e compromisso; silenciar rumores e boatos; e motivar a equipe para agir e desencadear determinadas ações.

Perspectivas em Gestão \& Conhecimento, João Pessoa, v. 7, n. 1, p. 28-47, jan./jun. 2017. 
Em relação ao subelemento práticas, ele refere-se às estratégias utilizadas pela organização que favorecem as trocas de conhecimento.

A etapa de percepção acontece durante o acompanhamento do ambiente organizacional, e busca identificar como o emissor percebe que o receptor compreendeu e assimilou a mensagem, a fim de garantir que os propósitos estabelecidos com o compartilhamento sejam atingidos ou se é necessário realizar nova inferência (TONET; PAZ, 2006; BRUSAMOLIN, 2006).

As práticas de controle tem por objetivo identificar as ações regulares de controle implementadas pelas empresas para garantir que o novo conhecimento seja institucionalizado (TONET; PAZ, 2006; BRUSAMOLIN, 2006).

\section{(5) Fontes}

Fontes são os fatores geradores de argumentações e explicações que fazem parte da explanação da mensagem compartilhada, para se conseguir chegar próximo da compreensão e ação (TONET; PAZ, 2006). As histórias são, com frequência, as fontes mais importantes de lições morais sobre o que deve-se ou não valorizar e sobre comportamentos que deve-se ter na organização (BRUSAMOLIN, 2006). Assim, o modelo visa identificar de onde se originam os componentes das narrativas organizacionais.

Com base em Brusamolin e Moresi (2008) as opções de fontes que podem ser empregadas nas construções das narrativas e que funcionam como argumentos, exemplos, metáforas e outras formas de persuasão, são: experiências vividas; livros, revistas ou jornais; televisão; novela, filmes, telejornais; histórias na própria empresa; sites na Internet, e-mail; conteúdo de treinamentos e cursos; ou criação, no sentido de criar uma história, exemplo, metáfora ou situação para facilitar o entendimento e fixar na memória.

\section{(6) Formas de interação}

As formas de interação são os canais (vias de acesso, situações, outros) e as condições como acontecem os fluxos de informação na narrativa entre os indivíduos na organização. As interações pelos canais são consideradas importantes, porque a criação do conhecimento está totalmente relacionada aos indivíduos e às interações estabelecidas entre eles (LINDE, 2001).

Tonet e Paz (2006) defendem que as interações para a troca de conhecimento podem ocorrer de forma sincrônica (quando o objetivo da interação for o de repassar conhecimentos do emissor para o receptor) ou diacrônica (quando o objetivo for o de procurar conhecimento para solucionar um problema em questão).

Para Brusamolin (2006), dependendo do propósito, as interações possam ocorrer por meio de: telefone, e-mail e redes sociais; sistema de gerenciamento da empresa (software) e/ou repositórios internos de documentos (virtuais e/ou físicos); conversas individuais e em grupo; conversa durante o expediente, fazendo parte da rotina e em treinamentos específicos; conversa planejada e estruturada de acordo com objetivos definidos; forma sincrônica e diacrônica e; local exclusivo ou sala exclusiva.

\section{(7) Mecanismos de suporte}

Mecanismos de suporte são outras estratégias ou modos de compartilhar conhecimento, cuja identificação é importante, pois situações típicas de compartilhamento, muitas vezes, envolvem uma combinação de métodos para gerar maior capacidade de ação e melhores resultados (SOLE; WILSON, 2002).

Com base em Sole e Wilson (2002) identifica-se que a narrativa pode ser sustentada pelos seguintes métodos:

Perspectivas em Gestão \& Conhecimento, João Pessoa, v. 7, n. 1, p. 28-47, jan./jun. 2017. 
- narrativa de histórias (storytelling): compartilhamento de conhecimentos e experiências por meio de narrativas de histórias para comunicar lições, ideias complexas, conceitos e conexões causais;

- modelagem: compartilhamento de conhecimentos e experiência por meio de exposição (ex. orientação, comportamento, e demonstrações e oportunidades específicas para observação);

- simulações: compartilhamento de conhecimentos e experiências por meio de situações vivenciais que recriam as complexidades da ação;

- recursos codificados: compartilhamento de conhecimento por meio de referência às fontes formais, documentos, manuais, bases de dados;

- objetos simbólicos: compartilhamento de conhecimento por meio da exposição a imagens, diagramas ou objetos, que representam ou ilustram o conhecimento ou ideia.

\section{(8) Barreiras}

O compartilhamento de conhecimento nas organizações sofre a influência de várias barreiras, que podem dificultar esse processo de diferentes formas. Com base em Tonet e Paz (2006), Denning (2006) e Brusamolin (2006), as barreiras podem estar relacionadas a todas as fases do compartilhamento de conhecimento, como por exemplo: a falta de tempo para pensar em um discurso/história ou para conversar e interagir podem impactar na iniciação e implementação do processo de compartilhamento; a resistência do receptor em adquirir o conhecimento, devido a não estar disposto a mudar a forma como trabalha, por sentir desconforto em colocar-se na posição de aprendiz, por temer não assimilar a nova aprendizagem, também prejudica para que se consolide a implementação; treinamento insuficiente dos usuários para a aplicação do conhecimento prejudicam as fases de apoio e incorporação do conhecimento.

A apresentação de cada elemento do modelo desenvolvido tem como proposta oferecer subsídios para se compreender a narrativa no fluxo de informação para o compartilhamento de conhecimento e auxiliar a reflexão e análise da narrativa na prática organizacional. A importância do modelo reside no fato de se apoiar no processo de compartilhamento e identificar elementos, permitindo uma sistematização da narrativa no fluxo de informação para sustentar o processo de melhoria das MPEs.

Todavia, com base no descrito e considerando que existem diversas formas de observar o objeto deste estudo (narrativa no fluxo de informação) em um contexto específico (no processo de compartilhamento de conhecimento organizacional), é relevante evidenciar que os elementos definidos e apresentados no modelo da narrativa no fluxo de informação, são resultados da compreensão obtida a partir da revisão de literatura. Sendo assim, é possível que outros elementos e aspectos possam ser englobados de tal modo que as categorias apresentadas neste estudo não se constituam na única forma de observar o tema.

\section{CONSIDERAÇÕES FINAIS}

Neste artigo, considerando o compartilhamento de conhecimento advindo do gestorproprietário um aspecto essencial para a criação de valor e competitividade das MPEs, agregou-se aos estudos sobre fluxo de informação a perspectiva da narrativa para o compartilhamento de conhecimento.

O modelo desenvolvido descreve como a narrativa acontece no fluxo de informação para o compartilhamento de conhecimento. Este entendimento auxilia na reflexão e análise da 
narrativa como prática organizacional, que permite ao gestor utilizá-la como um método de compartilhamento de conhecimento.

No que se refere às melhorias nos processos de serviços das MPEs, o modelo auxilia o gestor a definir seu posicionamento em relação a cada elemento (emissor, receptor(es), mensagem (narrativa), fontes de argumento, formas de interação, mecanismos de suporte e barreiras) e, com isso, permite validar sua estrutura de gestão como suporte às narrativas no fluxo de informação para o compartilhamento de conhecimento.

A relevância do modelo reside no fato de se apoiar nas etapas do processo de compartilhamento de conhecimento e indicar os parâmetros de análise na descrição dos elementos de forma concisa, permitindo uma sistematização da narrativa como um método capaz de sustentar o processo de melhoria das MPEs. Numa aplicação do modelo em um conjunto de MPEs, foi possível observar que ele se demonstrou adequado, coerente e consistente, para auxiliar no entendimento de como a narrativa acontece para compartilhar conhecimento e seu potencial na melhoria de práticas organizacionais (SANTOS, 2014).

Alguns dos resultados do compartilhamento de conhecimento identificados no ambiente organizacional, e também conforme apontado por Choo (2003) são: facilitar a tomada de decisão; reduzir o grau de incerteza; construir novos significados e compromissos com determinados cursos de ação, ou seja, ampliar as capacidades e habilidades das MPEs a partir de estímulos conduzidos pela articulação de conhecimentos entre gestores e equipe. Nesse sentido, o modelo atua na estruturação da narrativa para que esse processo se mantenha ativo no alcance dos propósitos organizacionais. Para isso, o modelo estabelece um caminho mediante a oferta de elementos que servem de base para que o gestor possa monitorar o ambiente e identificaras oportunidades para interagir e compartilhar conhecimento. Com base no gap identificado, os propósitos da narrativa são elencados e o gestor direciona-se para estudar uma melhor estratégia de interação, além de identificar as principais práticas que podem ser empregadas para estabelecer um contexto propício à criação e compartilhamento de conhecimento, acompanhando os resultados para que a assimilação e a replicação se efetivem na organização.

A construção narrativa de um gestor, para ser coerente e impactar o processo de compartilhamento de conhecimento organizacional precisa estar explicitada, de alguma forma, na estrutura de gestão, como por exemplo, no modo como estabelece a frequência das reuniões e momentos para trocas de ideias, na maneira como valoriza o trabalho em equipe, e como demonstra o respeito por outros pontos de vista. Deste modo, o compartilhamento de conhecimento em MPEs, que muitas vezes tende a ser difícil devido à rotina multitarefas dos seus gestores que, na maioria das vezes, participam ativamente do processo operacional dos negócios, pode melhorar com o suporte da narrativa que auxilia na interação e no acompanhamento dos resultados das práticas colocadas em ação.

Nesse contexto, o modelo oferece maneiras de trabalhar essa lacuna, a partir da análise dos elementos "Formas de interação" e "Mecanismos de suporte", para que os gestores repensem se a forma como as interações ocorrem valorizam ou não o conhecimento compartilhado; se conseguem identificar o que sustenta o compartilhamento em suas organizações e se, de fato, apresentam-se qualificados para atender o propósito de melhorias. Adicionalmente, é possível que os gestores realizem uma autoavaliação em relação aos aspectos da sua postura, que podem servir como facilitadores ou barreiras, e trabalhá-las positivamente, por estarem envolvidos pelo processo de compartilhamento de conhecimentos.

O planejamento da narrativa é amparado pelo modelo desenvolvido, iniciando pelo elemento "Monitoramento do ambiente" que instiga o gestor a estabelecer sua lista de prioridades de compartilhamento de conhecimento, após repensar seu posicionamento como líder fomentador ou mantenedor do negócio, ou seja, a questionar-se sobre quais tipos de

Perspectivas em Gestão \& Conhecimento, João Pessoa, v. 7, n. 1, p. 28-47, jan./jun. 2017. 
conhecimentos pretende trabalhar; como oferecerá manutenção para que o conhecimento permaneça disponível na empresa e; se os resultados alcançados com o esforço de criar e/ou manter o fluxo da narrativa agregam valor ao negócio.

O modelo suporta a sistematização das práticas de melhoria contínua das MPEs, contribuindo para a sustentabilidade organizacional, por meio de narrativas para o compartilhamento do conhecimento, auxiliando os gestores no modo como trabalha e articula seus conhecimentos, de forma inteligente e coletivamente entre os membros da organização.

Finalmente, este modelo contribui na prática e entendimento, de como e a partir de quais elementos a narrativa acontece no fluxo de informação, para o compartilhamento de conhecimento, buscando sustentar o desenvolvimento de processos e melhores práticas de serviços em MPEs. $O$ estudo deixa como contribuição uma nova perspectiva para analisar o fluxo de informação no ambiente das MPEs, com a inserção da narrativa.

\section{REFERÊNCIAS}

ALE EBRAHIM, N.; AHMED, S.; TAHA, Z. Virtual R\&D teams and SMEs growth: a comparative study between Iranian and Malaysian SMEs. African Journal of Business Management, Nigéria, v. 4, n. 11, p. 2368-2379, 2010.

BARRETO A. A. A informação em seus momentos de passagem. Revista de Ciência da Informação, Rio de Janeiro, v. 2, n. 4, ago. 2001. Disponível em: http://ridi.ibict.br/bitstream/123456789/171/1/BarretoDataGramaZero2001.pdf. Acesso em: 10 jun. 2014.

BARRETO A. A. A questão da informação. São Paulo em Perspectiva, São Paulo, v. 8, n. 4, p. 3 8, 1994.

BARRetO A. A. O rumor do conhecimento. São Paulo em Perspectiva, São Paulo, v. 12, n. 4, p. 69-77, 1999.

BARRETO A. A. O tempo e o espaço da ciência da informação. Transinformação, Campinas, v. 14, n.1, p. 17-24, 2002.

BOISOT, M. Knowledge assets: securing competitive advantage in the information economy. Oxford: Oxford University Press, 1998.

BOISOT, M. H.; LI, Y. Organizational versus markets knowledge: from concrete embodiment to abstract representation, Journal of Bioeconomics, v. 8, n. 3, p. 219-251, 2006.

BOISOT, M. H.; MACMILLAN, I. C.; HAN, K. S. Explorations in information space: knowledge, agents, and organization. New York: Oxford University Press, 2007.

BRUSAMOLIN, V. A inserção do discurso narrativo no ciclo informacional e seu impacto na aprendizagem organizacional. 2011. 312 f. Tese (Doutorado em Ciência da Informação) Universidade de Brasília, Brasília, DF, 2011.

Emprego de narrativas de histórias na gestão de projetos de tecnologia da informação. 2006. 143 f. Dissertação (Mestrado em Gestão do Conhecimento e da Tecnologia da Informação) - Universidade Católica de Brasília, Brasília, DF, 2006.

Perspectivas em Gestão \& Conhecimento, João Pessoa, v. 7, n. 1, p. 28-47, jan./jun. 2017. 
BRUSAMOLIN, V.; MORESI, E. Narrativas de histórias: um estudo preliminar na gestão de projetos de tecnologia da informação. Ciência da Informação, Brasília, DF, v. 37, n. 1, p. 37-52, 2008.

CHOO, C. W. A organização do conhecimento: como as organizações usam a informação para criar significado, construir conhecimento e tomar decisões. São Paulo: Senac, 2006.

CUNHA, I. B. A.; PEREIRA, F. C. M.; NEVES, J. T. R. Análise do fluxo informacional presente em uma empresa do segmento de serviços de valor agregado (SVA). Perspectivas em Ciência da Informação, João Pessoa, v. 20, n. 4, p. 107-128, 2015.

CURTY, R. G. O fluxo da informação tecnológica no projeto de produtos em indústrias de alimentos. 2005. 249 f. Dissertação (Mestrado em Ciência da Informação) - Universidade Federal de Santa Catarina, Florianópolis, 2005.

DENNING, S. O poder das narrativas nas organizações: o guia para líderes sobre o uso da técnica de narrativas. Rio de Janeiro: Elsevier Brasil: Petrobras, 2006.

DURST, S.; EDVARDSSON, I. R. Knowledge management in SMEs: a literature review. Journal of Knowledge Management, v. 16, n. 6, p. 879-903, 2012.

ECHEVERRÍA, R. Diálogo e ética nas organizações. Instituto Ethos Revista Reflexão, ano 5, n.13, out. 2004.

GARGIULO, T. L. Stories at work: using stories to improve communication and build relationships. USA: Praeger Publishers, 2006.

GASSMANN, O.; KEUPP, M. M. The competitive advantage of early and rapidly internationalizing SMEs in the biotechnology industry: a knowledge-based view. Journal of World Business, v. 42, n. 3, p. 350-366, 2007.

GIL, A. C. Como elaborar projetos de pesquisa. 4. ed. São Paulo: Atlas, 2002.

GONÇALVES, C. O.; RAMOS, D. S. F.; SANTOS, M. S. Gestão do conhecimento e comunicação organizacional: estudo da aplicação de um modelo de comunicação organizacional para disseminação do conhecimento. 2009. 83 f. Dissertação (Mestrado em Gestão do Conhecimento e Inteligência Empresarial) - Universidade Federal do Rio de Janeiro, 2009.

INOMATA, D. O.; ARAÚJO, W. C. O.; VARVAKIS, G. Fluxos de informação na perspectiva organizacional. Informação \& Informação, Londrina, v. 20, n. 3, p. 203-228, 2015.

INOMATA, D. O. O fluxo da informação tecnológica: uma análise no processo de desenvolvimento de produtos biotecnológicos. 2012. 282 f. Dissertação (Mestrado em Ciência da Informação) - Universidade Federal de Santa Catarina, Florianópolis, 2012.

JORGE, C. F. B.; VALENTIM, M. L. P. A importância do mapeamento das redes de conhecimento para a gestão da informação e do conhecimento em ambientes esportivos: um estudo de caso no Marília Atlético. Perspectivas em Ciência da Informação, v. 21, n. 1, p. 152-172, 2016. 
LESCA, H.; ALMEIDA, F. C. Administração estratégica da informação. Revista de Administração da FEA/USP, São Paulo, v. 29, n. 3, p. 66-75, jul./set. 1994.

LINDE, C. Narrative and social tacit knowledge. Journal of Knowledge Management, v. 5, n. 2, p. 160-171, 2001.

MARCONI, M. A.; LAKATOS, E. M. Técnicas de pesquisa: planejamento e execução de pesquisas, amostragens e técnicas de pesquisa, elaboração, análise e interpretação de dados. 6. ed. rev. ampl. São Paulo: Atlas, 2007.

NASCIMENTO, N. M. et al. Gerenciamento dos fluxos de informação como requisito para a preservação da memória organizacional: um diferencial competitivo. Perspectivas em Gestão \& Conhecimento, João Pessoa, v. 6, n. 1, p. 29-44, 2016.

NONAKA, I. A empresa criadora de conhecimento. In: Harvard Business Review. Gestão do Conhecimento. 5. ed. Rio de Janeiro: Campus, 2000, p. 27-80.

PASSOS, K. G. F. O fluxo de informação no processo de desenvolvimento de jogos eletrônicos. 2012. 223 f. Dissertação (Mestrado em Ciência da Informação) - Universidade Federal de Santa Catarina, Florianópolis, 2012.

SANTARÉM, V.; VITORIANO, M. C. C. P. Gestão da informação, fluxos informacionais e memória organizacional como elementos da inteligência competitiva. Perspectivas em Gestão \& Conhecimento, João Pessoa, v. 5, Número Especial, p. 158-170, jan. 2016.

SANTOS, C. D.; VALENTIM, M. L. P. As interconexões entre a gestão da informação e a gestão do conhecimento para o gerenciamento dos fluxos informacionais. Perspectivas em Gestão \& Conhecimento, João Pessoa, v. 4, n. 2, p. 19-33, jul./dez. 2014.

SANTOS, T. C. S. Narrativa no fluxo de informação durante o compartilhamento durante o compartilhamento de conhecimento em MPEs: um estudo multicaso nos núcleos setoriais e câmaras da ACIF. 2014. 202 f. Dissertação (Mestrado em Ciência da Informação) Universidade Federal de Santa Catarina, Florianópolis, 2014.

SCHREIBER, D. Compartilhamento do conhecimento entre contratante e contratado no processo de externalização de atividades de P\&D. Perspectivas em Gestão \& Conhecimento, João Pessoa, v. 5, n. 2, p. 127-146, jul./dez. 2015.

SOLE, D.; WILSON, D. G. Storytelling in organizations: the power and traps of using stories to share knowledge in organizations. LILA, Harvard, Graduate School of Education, 2002.

STRAUSS, A. L.; CORBIN, J. M. Pesquisa qualitativa: técnicas e procedimentos para o desenvolvimento de teoria fundamentada. 2. ed. Porto Alegre: Artmed, 2008.

THORPE, R. et al. Using knowledge within small and medium-sized firms: A systematic review of the evidence. International Journal of Management Reviews, v. 7, n. 4, p. 257-281, 2005.

TONET, H. C.; PAZ, M. G. T. Um modelo para o compartilhamento de conhecimento no trabalho. Revista de Administração Contemporânea - RAC, Curitiba, v. 10, n. 2, p. 75-94, abr./jun. 2006.

Perspectivas em Gestão \& Conhecimento, João Pessoa, v. 7, n. 1, p. 28-47, jan./jun. 2017. 
VALENTIM, M. L. (Org.). Gestão, mediação e uso da informação. São Paulo: Cultura Acadêmica, 2010.

WANG, Y.; COSTELLO, P. An investigation into innovations in SMEs: evidence from the West Midlands, UK. Journal of Entrepreneurship, v. 18, n. 1, p. 65-93, 2009. Disponível em: http://ioe.sagepub.com/cgi/doi/10.1177/097135570801800104. Acesso em: 15 jul. 2011.

WANG, Y. L.; WANG, Y.; HORNG, R. Y. Learning and innovation in small and medium enterprises. Industrial Management \& Data Systems, v. 110, n. 1-2, p. 175-192, 2010.

WEICK, K. E.; SUTCLIFFE, K. M.; OBSTFELD, D. Organizing and the process of sensemaking. Organization Science, v. 16, n. 4, p. 409-421, 2005.

WONG, K. Y.; ASPINWALL, E. An empirical study of the important factors for knowledgemanagement adoption in the SMEs sector. Journal of Knowledge Management, v. 9, n. 3, p. 64-82, 2005. 